\title{
Unanticipated discovery of two rare gastropod molluscs from recently located hydrothermally influenced areas in the Okinawa Trough
}

\author{
Chong Chen ${ }^{\text {Corresp., }}$ 1 , Hiromi Kayama Watanabe $^{2,3,4}$, Junichi Miyazaki ${ }^{1,3,4}$, Shinsuke Kawagucci ${ }^{1,3,4}$ \\ 1 Department of Subsurface Geobiological Analysis and Research, Japan Agency for Marine-Earth Science and Technology, Yokosuka, Kanagawa, Japan \\ 3 Research and Development Center for Submarine Resources, Japan Agency for Marine-Earth Science and Technology, Yokosuka, Kanagawa, Japan \\ 4 Project Team for Development of New-generation Research Protocol for Submarine Resources, Japan Agency for Marine-Earth Science and Technology, \\ Yokosuka, Kanagawa, Japan \\ Corresponding Author: Chong Chen \\ Email address: cchen@jamstec.go.jp
}

Background. Deep-sea hydrothermal vent is one of the most 'extreme' environments in the marine realm. Few species are capable of inhabiting such ecosystems, despite extremely high productivity there supported by microbial chemosynthesis, leading to high biomass and low species richness. Although gastropod molluscs are one of the main constituents of megafaunal communities at vent ecosystems, most species belong to several typical families (e.g., Provannidae, Peltospiridae, Lepetodrilidae) specialised and adapted to life at vents.

Methods. During recent surveys of Okinawa Trough hydrothermal vent systems, two snails atypical of vent ecosystems were unexpectedly found in newly discovered hydrothermally influenced areas. Shell and radular characteristics were used to identify the gastropods morphologically.

Results. One species was a vetigastropod, the calliostomatid Tristichotrochus ikukoae (Sakurai, 1994); and the other was a caenogastropod, the muricid Abyssotrophon soyoae (Okutani, 1959). Both gastropods were previously only known from regular non-chemosynthetic deep-sea and very rare - only two published records exist for each species. The radula formula of Tristichotrochus ikukoae is accurately reported for the first time and based on that it is returned to genus Otukaia. For both species, barcode sequences of the cytochrome $c$ oxidase I (COI) gene were obtained and deposited for future references.

Discussion. These new records represent the second record of calliostomatids from vents (third from chemosynthetic ecosystems) and the third record of muricids from vents (tenth from chemosynthetic ecosystems), and extend the distribution of both species to the southwest. Neither family has been recorded at chemosynthetic ecosystems in the western Pacific. Both were from weakly diffuse flow areas not subject to high temperature venting but were nevertheless associated with typical vent-reliant taxa such as Lamellibrachia tubeworms and Bathymodiolus mussels. These new records show that these species are capable of tolerating environmental stress associated with weak hydrothermally influenced areas, despite not being vent endemic species, adding to the list of known vent/non-vent species intersections. This signify that such weakly influenced areas may provide key habitats for them, and that such areas may play a role in the evolution of biological adaptations to 'extreme' chemosynthetic ecosystems. 
2 Unanticipated discovery of two rare gastropod molluscs from recently located hydrothermally influenced areas in the Okinawa Trough

4 Chong Chen ${ }^{1 *}$, Hiromi Kayama Watanabe ${ }^{2,3,4}$, Junichi Miyazaki ${ }^{1,3,4}$, Shinsuke 5 Kawagucci ${ }^{1,3,4}$ Marine-Earth Science and Technology (JAMSTEC), 2-15 Natsushima, Yokosuka 237-0061, Japan ${ }^{2}$ Department of Marine Biodiversity Research (BIO-DIVE), Japan Agency for Marine-Earth Science and Technology (JAMSTEC), 2-15 Natsushima-cho, 237-0061 Yokosuka, Japan

${ }^{3}$ Research and Development Center for Submarine Resources, Japan Agency for Marine-Earth Science and Technology (JAMSTEC), 2-15 Natsushima-cho, 237-0061 Yokosuka, Japan ${ }^{4}$ Project Team for Development of New-generation Research Protocol for Submarine Resources, Japan Agency for Marine-Earth Science and Technology (JAMSTEC), 2-15 Natsushima-cho, 237-0061 *Corresponding author. Tel: +81-(0)46-867-9717; E-mail: cchen@jamstec.go.jp

16 Short title: Two gastropods newly recorded from vents 
18 Background. Deep-sea hydrothermal vent is one of the most 'extreme' environments in the marine realm. Few species are capable of inhabiting such ecosystems, despite extremely high productivity there supported by microbial chemosynthesis, leading to high biomass and low species richness. Although gastropod molluscs are one of the main constituents of megafaunal communities at vent ecosystems, most species belong to several typical families (e.g., Provannidae, Peltospiridae, Lepetodrilidae) specialised and adapted to life at vents.

24 Methods. During recent surveys of Okinawa Trough hydrothermal vent systems, two snails atypical of vent ecosystems were unexpectedly found in newly discovered hydrothermally influenced areas. Shell and radular characteristics were used to identify the gastropods morphologically.

Results. One species was a vetigastropod, the calliostomatid Tristichotrochus ikukoae (Sakurai, 1994); and the other was a caenogastropod, the muricid Abyssotrophon soyoae (Okutani, 1959). Both gastropods were previously only known from regular non-chemosynthetic deep-sea and very rare - only two published records exist for each species. The radula formula of

32 Tristichotrochus ikukoae is accurately reported for the first time and based on that it is returned to genus Otukaia. For both species, barcode sequences of the cytochrome $c$ oxidase I (COI) gene were obtained and deposited for future references.

Discussion. These new records represent the second record of calliostomatids from vents (third from chemosynthetic ecosystems) and the third record of muricids from vents (tenth from chemosynthetic ecosystems), and extend the distribution of both species to the southwest. Neither family has been recorded at chemosynthetic ecosystems in the western Pacific. Both were from weakly diffuse flow areas not subject to high temperature venting but were nevertheless associated with typical vent-reliant taxa such as Lamellibrachia tubeworms and Bathymodiolus mussels. These new records show that these species are capable of tolerating environmental stress associated with weak hydrothermally influenced areas, despite not being vent endemic species, adding to the list of known vent/non-vent species intersections. This signify that such weakly influenced areas may provide key habitats for them, and that such areas may play a role in the evolution of biological adaptations to 'extreme' chemosynthetic ecosystems. 
47 Deep-sea hydrothermal vents exhibit increased water temperature, higher heavy metal 48 concentrations, and raised concentrations of substances acting as energy sources for 49 chemosynthesis (such as $\mathrm{H}_{2}, \mathrm{CH}_{4}, \mathrm{H}_{2} \mathrm{~S}$ ) compared to the surrounding water (Van Dover, 2000; 50 Petersen et al., 2011). Due to such 'extreme' environmental conditions, few species are capable 51 of inhabiting such ecosystems, despite extremely high productivity there for the deep-sea 52 supported by microbial chemosynthesis (Grassle, 1987). As a result, although vent ecosystems 53 support biomass comparable even to that of shallow water coral reefs, the macro- and megafaunal 54 communities there are characterised by a low species richness (Lutz \& Kennish, 1993; Van Dover $55 \&$ Trask, 2000).

56 Although gastropod molluscs are one of the main constituents of megafaunal communities at 57 hydrothermal vent ecosystems, species present mostly to belong to one of several typical families 58 (e.g., Provannidae, Peltospiridae, Lepetodrilidae) specialised and adapted to life at vent and other 59 chemosynthetic ecosystems such as hydrocarbon seeps and organic falls (Sasaki et al., 2010). 60 Here, we report new records of two gastropod species, Tristichotrochus ikukoae (Sakurai, 1994) 61 (Vetigastropoda: Calliostomatidae) and Abyssotrophon soyoae (Okutani, 1959) 62 (Caenogastropoda: Muricidae), from two new diffuse flow hydrothermal sites discovered using 63 the multibeam echo-sounding (MBES) method (as outlined in Nakamura et al., 2015). Both 64 species are exceedingly rare endemics of Japan, with only two published records each.

65 Calliostomatidae is an exclusively marine family of usually grazing gastropods which comprises about 300 extant species (Marshall, 1995; Vilvens, 2014; Marshall, 2016). Only two species have been recorded from chemosynthetic ecosystems, one from vent and one from seep (Sasaki et al., 2010). Muricidae is a large family of carnivorous and generally predatory marine caenogastropods comprising about 1600 living species (Merle et al., 2011). A total of seven muricids have been recorded from hydrocarbon seeps, but none from vents (Sasaki et al., 2010) and two species (Enixotrophon carduelis (Watson, 1882) and E. obtusus (Marshall \& Houart, 2011) were recorded from Rumble V Volcano which is a hydrothermally influenced area on the Kermadec Ridge (Marshall \& Houart, 2011). The present study, therefore, presents the second record of Calliostomatidae and the third record of Muricidae from hydrothermal vent ecosystems.

The two species newly recorded from vents herein are unlikely to be vent endemics but are clearly interacting with vent environment and other vent endemic fauna. These records add to the intersection of vent endemic and non-vent endemic species in the peripheral diffuse flow environment, where non-endemic species have often been recorded due to the much less stressful 
79 environment compared to focused flow venting (reviewed in Levin et al., 2016).

81 Potential signals of hydrothermal activity were detected in the Okinawa Trough by detecting 82 acoustic water column anomalies, probably derived from $\mathrm{CO}_{2}$ bubbles discharging from vents, 83 using an EM122 (Kongsberg Maritime) MBES system on R/V Yokosuka (cruises YK14-16 and 84 YK16-07), as outlined in Nakamura et al. (2015). The signals were then ground-truthed with 85 Remotely Operated Vehicle (ROV) KAIKO (with vehicle Mk-IV) dives on-board R/V Kairei 86 during cruises KR15-16 (Kawagucci et al., 2015; Makabe et al., 2016) and KR16-16 (Miyazaki 87 et al., 2016; Makabe et al., 2017). A suction sampler equipped on the ROV KAIKO was used to 88 collect the gastropods. A digital camera mounted on the same ROV was used to shoot the in situ 89 observation images.

90 Upon recovery on to the research vessel, the specimens were fixed and stored in $99 \%$ ethanol for 91 subsequent studies. Amplification and sequencing of the cytochrome $c$ oxidase I (COI) barcode 92 gene was done using a piece of foot using the universal primer pair LCO1490 and HCO2198 93 (Folmer et al., 1994). Molecular methods follow that outlined in Chen et al (2016). After taking 94 tissue snips, soft parts were extracted from the specimens after rehydrating in MilliQ. The radula 95 was dissected out from each specimen under a dissecting microscope (Olympus SZX1) and 96 cleaned by washing in diluted commercial bleach followed by two washes, in MilliQ water and 97 99\% ethanol each. The cleaned radulae were mounted on SEM stubs with carbon tapes and 98 examined uncoated at $15 \mathrm{kV}$ with a table top scanning electron microscope (SEM; Hitachi TM99 3000).

\section{Results and Discussion}

\section{Detection and discovery of hydrothermal sites}

102 One acoustic anomaly ( $28^{\circ} 26.1^{\prime} \mathrm{N}, 128^{\circ} 11.5^{\prime} \mathrm{E}$; Fig. 1) was detected in the northern Okinawa 103 Trough near Tokara Islands, in the 'Higashi-Ensei' area (Makabe et al., 2017) east-northeast of 104 Minami-Ensei Knoll (Hashimoto et al., 1995). This site was explored on dive \#724 of ROV 105 Kaiko, which discovered a weakly active hydrothermal vent site mostly with diffuse flow areas. 106 This site was 955-1180 m deep, dominated by dense Lamellibrachia tubeworm bushes grown 
107 over by the barnacles Ashinkailepas seepiophila Yamaguchi, Newman \& Hashimoto, 2004 and

108 Leucolepas longa Southward \& Jones, 2003, and was named 'Fukai' (Fig. 2A; for details see 109 Miyazaki et al., 2016; Makabe et al., 2017). Other fauna typical of Okinawa Trough 110 hydrothermal vents (Watanabe \& Kojima, 2015), such as the squat lobster Shinkaia crosnieri 111 Baba \& Williams, 1998, the vesicomyid clam Akebiconcha kawamurai Kuroda, 1943, and the 112 mussel Bathymodiolus platifrons Hashimoto \& Okutani, 1994 were also present in this site. 113 Another signal $\left(25^{\circ} 4.5^{\prime} \mathrm{N}, 124^{\circ} 31.0^{\prime} \mathrm{E}\right.$; Fig. 1) was located about 1950-1990 $\mathrm{m}$ deep on the 114 northern slope of Tarama Hill in the southern Okinawa Trough, and was surveyed during ROV 115 KAIKO dive \#669 (for details see Makabe et al., 2016). A small weakly hydrothermally 116 influenced site dominated by white branching Poecilosclerida sponges (sensu Ise, 2012), Alaysia 117 sp. and Lamellibrachia sp. tubeworms, and Bathymodiolus aduloides Hashimoto \& Okutani, 1181994 mussels was found and named 'Crane' (Fig. 2C; Makabe et al., 2017).

\section{Tristichotrochus ikukoae (Sakurai, 1994)}

120 One specimen of a calliostomatid gastropod was collected from Fukai site, Higashi-Ensei, 121 Okinawa Trough (28 26.1064’ N, 124 $11.4889^{\prime}$ E, 962 m deep, R/V Kairei cruise KR16-16, 122 ROV KAIKO Dive \#724, 2016/xii/04). Based on shell (diameter 22.6 mm, height $21.2 \mathrm{~mm}$; Fig. 123 3A-D) and radular (Fig. 4A) characteristics this specimen was clearly identifiable as 124 Tristichotrochus ikukoae (Sakurai, 1994). To the knowledge of the authors, this is only the third 125 time it has been formally reported in the literature (Higo et al., 1999; Hasegawa, 2009). A total of 126 three individuals were sighted at the same site (Fig. 2B), living attached on Lamellibrachia sp. 127 tubeworm tubes or hard surrounding substrata.

128 The taxonomic history of Tristichotrochus ikukoae is rather perplexing. It was initially described 129 from Kochi Prefecture, Japan as Otukaia ikukoae Sakurai, 1994. Sakurai compared it to Otukaia 130 kiheiziebisu (Otuka, 1939), commenting that O. ikukoae is 'smaller in size, and has obtuser ribs 131 with larger granules' as well as 'has only 21 basal ribs in comparison' to O. kiheiziebisu (Sakurai, 132 1994). Later, Okutani \& Iwahori (1992) reported O. kiheiziebisu from Tosa Bay, Kochi 133 Prefecture, Japan which extended its distribution range from Sagami Bay. They reported that their 134 specimens were variable in spiral rib development, with some specimens exhibiting five equally 135 strong ribs. Radulae of such 'unusual' specimens were illustrated (Okutani \& Iwahori, 1992: figs. 136 7, 10-12), and were actually virtually identical to the holotype of $O$. ikukoae. Following this, 137 Hasegawa \& Saito (1995) considered O. ikukoae to be a junior synonym of $O$. kiheiziebisu, and 138 Hasegawa (2009) formally synonymised the two species. More recently, however, Marshall 139 (2016) figured the radula of a typical O. kiheiziebisu and found it to be clearly distinct from that 
140 figured by Okutani \& Iwahori (1992). Otukaia ikukoae was reinstated as a valid species and 141 transferred to Tristichotrochus based on its fewer lateral teeth compared to Otukaia (four to six 142 compared to nine in O. kiheiziebisu).

143 Though the radula of T. ikukoae was reported to have only four pairs of lateral teeth (Okutani \& 144 Iwahori, 1992) compared to nine in O. kiheiziebisu (Marshall, 2016), this was questioned by 145 Marshall (2016) who reasoned that there may actually be as many as five to six pairs. The 146 specimen of T. ikukoae investigated in the present study has eight pairs of laterals (Fig. 4A), 147 which is more numerous than Marshall (2016) predicted and makes the radula formula $148(n+8+1+8+n)$. Due to only a single specimen being collected it is not possible to comment on the 149 intraspecific variation in the radula of T. ikukoae at this point, but this is the most reliable account 150 of the radula characteristics of this rare calliostomatid. Having as many as eight pairs of laterals 151 means the radula of T. ikukoae actually fits well in genus Otukaia, and it is therefore returned to 152 that genus herein, as Otukaia ikukoae Sakurai, 1994.

153 It should be noted that O. ikukoae and O. kiheiziebisu are in fact easily distinguished by shell 154 characteristics as well, by the following two points: 1. O. ikukoae has five to six strong ribs on 155 the body whorl whereas $O$. kiheiziebisu only has two to three (including the base keel); 2 . The 156 ribs of O. ikukoae are less sharply raised but more strongly beaded than those of O. kiheiziebisu. 157 To assist future identification of these two species based on molecular barcodes, a COI barcode 158 of the present specimen was sequenced and deposited in DNA Data Bank of Japan (DDBJ; 159 accession number LC333137). A sequence of the same gene is already available on GenBank for 160 O. kiheiziebisu (from Williams, 2010) under the accession number AB505274, the identity of the 161 individual sequenced has been ascertained and confirmed as O. kiheiziebisu (T. Nakano pers. 162 comm., in Marshall, 2016). Based on comparison between these two sequences, the pairwise 163 difference between the two species is $5.8 \%$, which is higher than the average of $3-4 \%$ between 164 closely related species in marine gastropods (Meyer \& Pauley, 2005).

165 The size of the present specimen (shell height $21.2 \mathrm{~mm}$ ) is just slightly smaller than previous 166 reports as shell height of the holotype is $23.9 \mathrm{~mm}$ (Sakurai, 1994) and height of specimens 167 definitively referable to $O$. ikukoae reported by Okutani \& Iwahori (1992) range between 23.5 $168 \mathrm{~mm}-26.7 \mathrm{~mm}$.

169 Since O. ikukoae has not been recorded from outside Kochi Prefecture (Higo et al., 1999; 170 Hasegawa, 2009), the present new record extends its distribution range to the southwest by about $171700 \mathrm{~km}$. The collection depth of $962 \mathrm{~m}$ is deeper than the Tosa Bay record (700 m; Okutani \& 
172 Iwahori, 1992), and since the depth that the type specimen was collected from is not known 173 (Sakurai, 1994), this represents the deepest record for the species.

174 Abyssotrophon soyoae (Okutani, 1959)

175 Two specimens of trophonine muricids were collected from the Crane site, Tarama Hill, Okinawa 176 Trough $\left(25^{\circ} 4.5388^{\prime} \mathrm{N}, 124^{\circ} 31.0103^{\prime} \mathrm{E}, 1973 \mathrm{~m}\right.$ deep, R/V Kairei cruise KR15-16, ROV 177 KAIKO Dive \#669, 2015/x/29). A total of five individuals was sighted at this site (Fig. 2D). The 178 morphology of the two specimens matched best, in terms of shell (specimen \#1, height $22.2 \mathrm{~mm}$, 179 width $11.0 \mathrm{~mm}$, Fig. 3E-H; specimen \#1, height $22.5 \mathrm{~mm}$, width $10.5 \mathrm{~mm}$, Fig. 3I, J) and radular 180 (specimen \#1, Fig. 4B) characters, with Abyssotrophon soyoae (Okutani, 1959). Originally 181 described from off Miki-Saki, Kumano-nada, Kii Peninsula, Japan (33 $48.8^{\prime}$ N, $136^{\circ} 34.8^{\prime}$ E) as 182 Trophonopsis soyoae Okutani, 1959, this is only the third time it has been recorded formally 183 (Okutani \& Iwahori, 1992; Higo et al., 1999; Tsuchiya, 2017). Furthermore, three individuals that 184 appeared to belong to the same species were seen in Fukai site (Fig. 2B, the same location as $O$. 185 ikukoae collecting data above), but unfortunately none were collected.

186 Conchologically $A$. soyoae is easily recognised by two strong keels combined with very crowded axial ribs (Tsuchiya, 2017). One significant difference between the present material and previously reported specimens is that the axial ribs are less crowded (about 35 vs about 70; Okutani \& Iwahori, 1992). However, there appears to be some variability in rib frequency across life stages (see Fig. 3J; Okutani \& Iwahori, 1992: fig. 28) and the authors consider this difference to be intraspecific, rather than interspecific, variability until further evidence becomes available proving otherwise. The specimens examined herein also have higher spires than the holotype (Okutani, 1959), but they match well with specimens previously reported from Tosa Bay, Kochi Prefecture, Japan (Okutani \& Iwahori, 1992). The shell height to width ratios were 2.02 and 2.14, which gives an impression that they are more stout than the previous specimens which range between $2.11-2.69$ (2.11 in the holotype; Okutani \& Iwahori, 1992) but only because the earlier whorls are much more corroded in the present specimens, likely due to the acidic hydrothermal environment. The radula is very much the same as imaged by Okutani \& Iwahori (1992), including the formula $(1+1+1)$ and in having a single middle cusp on the central tooth. Although the soft parts of the specimens investigated were not of good quality, eyes were present in both individuals and the smaller individual (specimen \#1, male) possessed a very large penis as

202 previously reported (Okutani \& Iwahori, 1992). To facilitate future identification and genetic 203 comparison, the COI barcode sequence was obtained from specimen \#1 and deposited in DDBJ 
204 under accession number LC333138. The closest match available on GenBank is a sequence of

205 Boreotrophon truncatus (Strøm, 1768), accession number HQ919183 (from Layton et al., 2014)

206 with 9\% pairwise difference.

207 Since this species has only been reported from the type locality and Tosa Bay (Higo et al., 1999;

208 Tsuchiya, 2017), the present record extends its distribution range over $1250 \mathrm{~km}$ to the southwest.

209 The collection depth of the present record $(1973 \mathrm{~m})$ is within the bathymetric range between the

210 type locality (2050 m; Okutani, 1959) and the Tosa Bay record (700 - $750 \mathrm{~m}$; Okutani \& Iwahori,

211 1992).

\section{Significance of the new records from vent ecosystems}

213 Trochoid gastropods are commonly found in many hydrothermal vent sites around the globe (e.g.,

214 Iheyaspira, Cantrainea) but calliostomatids have only been recorded twice (Sasaki et al., 2010).

215 These include Falsimargarita nauduri Warén and Bouchet 2001 from the $17^{\circ} \mathrm{S}$ hydrothermal vent

216 site, East Pacific Rise (Warén \& Bouchet, 2001) and Maurea chilena (Rehder, 1971) from

217 Concepción methane seep off Central Chile (Sellanes et al., 2008). Although Sellanes et al.

218 (2008) also reported Otukaia crustulum Vilvens \& Sellanes, 2006 from the Concepción methane

219 seep, this species has been moved to Calliotropidae, as Calliotropis crustulum (Marshall, 2016).

220 The present report of Otukaia ikukoae is therefore the second record of calliostomatids from vent

221 ecosystems and the third record from chemosynthetic ecosystems.

222 Muricids are found from intertidal waters down to over $7000 \mathrm{~m}$ deep, and Abyssotrophon is one 223 of the deepest-living genera occurring even over $7200 \mathrm{~m}$ deep in the case of Abyssotrophon 224 hadalis (Sysoev, 1992) (Egorov, 1993). Five species of Muricidae are known from Concepción 225 methane seep off Central Chile (Sellanes et al., 2008) and two are known from methane seeps in 226 Barbados Prism (Warén \& Bouchet, 2001), making a total of seven records from hydrocarbon 227 seeps. Except Pagodula concepcionensis Houart \& Sellanes, 2006 which is in the subfamily 228 Pagodulinae (Houart \& Sellanes, 2006), all other six species recorded are in the subfamily 229 Trophoninae (genera Trophon and Coronium; Sasaki et al., 2010). The present record of 230 Abyssotrophon soyoae is the third record of this family from vent ecosystems and the tenth from 231 chemosynthetic ecosystems. Both families were previously unrecorded from chemosynthetic 232 ecosystems of not only the Okinawa Trough but the western Pacific as a whole (Sasaki et al., 233 2010; Watanabe \& Kojima, 2015).

234 Although the two species reported herein were found in hydrothermally influenced settings, they 
235 are also known from regular deep-sea bottom (Okutani \& Iwahori, 1992) and thus not endemic to 236 chemosynthetic ecosystems. Neither new hydrothermally influenced site reported herein is 237 vigorously active, and is instead more like 'hydrothermal seeps' (Levin et al., 2012) than 238 conventional high-temperature fluid venting systems. The presence $O$. ikukoae and A. soyoae in 239 weakly diffuse flow areas indicate that they are able to tolerate some levels of environmental 240 stresses associated with hydrothermal ecosystems (e.g., increased acidity, concentration of toxic substances and heavy metals), allowing them to invade and benefit from the high productivity of hydrothermal vent ecosystems.

243 While feeding behaviour was not observed in the field, the ecological roles the two species play 244 may be inferred as follows. Deep-water calliostomatids are mostly carnivorous grazers feeding on cnidarians or sponges (Marshall, 1995), and from the fact that they were observed living on tubeworm tubes $O$. ikukoae in Fukai site probably graze on sponges and/or biofilm growing on the tubes. Muricids are carnivores feeding on other marine invertebrates (Merle et al., 2011), and A. soyoae is unlikely to be an exception. In both localities the Abyssotrophon individuals were seen in close proximity to other molluscs (e.g., Bathymodiolus aduloides at Crane site) and barnacles (e.g., Ashinkailepas seepiophila at Fukai site) which the Abyssotrophon likely prey upon. In interacting with vent endemic species in such ways, O. ikukoae and $A$. soyoae may contribute to trophic transfer of chemosynthetically derived production from vents to surrounding ambient environment, which some other predators such as seastar, fish, and octopus have been suggested to play a role in (Levin et al., 2016 and references therein). The apparent absence of these two species from other Okinawa Trough vents is possibly an artefact caused by the relatively little effort put into exploring the peripheral areas.

In fact, non-vent endemic deep-water predatory gastropods have been recorded from vent periphery in several occasions, for example Buccinum viridum Dall, 1889 on the Juan de Fuca Ridge (Tunnicliffe \& Fontaine, 1987; Sarrazin et al., 1997), Enixotrophon carduelis and E. obtusus on the Kermadec Ridge (Marshall \& Houart, 2011), and Neptunea robusta Okutani, 1964 in the Okinawa Trough (Watanabe \& Kojima, 2015). Their success may be a combined effect of the ability to tolerate moderate environmental stress from vent periphery and the fact that few vent endemic gastropod species are predators, meaning there is an available niche for these predatory species given the high productivity. In the Okinawa Trough vents, for instance, only one vent endemic predatory gastropod, Thermosipho desbruyeresi (Okutani \& Ohta, 1993), is known (Watanabe \& Kojima, 2015).

267 The present records signify that outskirts of hydrothermally influenced areas likely provide 
268 important habitats and energy resources for some non-endemic species (Levin et al., 2016). These 269 peripheral areas may be important for the evolution of biological adaptations to chemosynthetic 270 ecosystems by providing the intermediate environment between 'extreme' vents and the regular 271 surrounding seafloor.

\section{Conclusions}

273 Exploration of two new hydrothermally influenced ecosystems in the Okinawa Trough led to the 274 collection of two gastropod snails previously unknown from chemosynthetic ecosystems. One 275 was Otukaia ikukoae, the second calliostomatid ever recorded from vents and the third record of the family for chemosynthetic ecosystems overall. The other was the muricid Abyssotrophon soyoae, marking the third time Muricidae has been found at hydrothermal vents and the tenth record at chemosynthetic ecosystems. Both species are extremely rare and this report represents the third record for each species in the literature as well as the first time they are seen in their natural habitat. Neither family has been recorded at chemosynthetic ecosystems in the western Pacific. Since both species are also known from regular non-chemosynthetic deep-sea and they were recovered from areas with only weak diffuse flow venting, they have most likely invaded vent environment from regular sea bottom and play a role in trophic transfer of chemosynthetic production to the surrounding seafloor. The fact that such species are able to tolerate (some) influence from hydrothermal vents signify that such 'outskirt' areas may provide key habitats for them, and that these areas may play a role in the evolution of biological adaptations to 'extreme' chemosynthetic ecosystems.

\section{Additional Information and Declarations}

289

290

291

292

293

294

\section{Data Availability}

Specimens studies in this study are deposited and accessioned at JAMSTEC marine biological sample collection; Otukaia ikukoae: JAMSTEC No. 1160052681; Abyssotrophon soyoae: JAMSTEC No. 1150046767. The newly generated COI barcode sequences are deposited in DNA Data Bank of Japan with accession numbers LC333137 (O. ikukoae) and LC333138 (A. soyoae). 
295 The authors would like to express their sincere gratitude to the Captain and crews of R/Vs Kairei 296 and Yokosuka, as well as the operation team of the ROV KAIKO, for their untiring support during 297 the relevant cruises (YK14-16, KR15-16, YK16-07, KR16-16). Kyoko Okino (AORI, the 298 University of Tokyo) is gratefully acknowledged for leading the YK14-16 cruise, and Kentaro 299 Nakamura (the University of Tokyo) for analysing the MBES data which led to the discovery of 300 the new hydrothermal sites. Roland Houart and Christopher Moe are thanked for their valuable 301 aid in identifying the Abyssotrophon. Kazuya Kitada (JAMSTEC) kindly provided the base map 302 for Fig. 1 used herein. Bruce Marshall (Museum of New Zealand Te Papa Tongarewa) and Verena 303 Tunnicliffe (University of Victoria) are thanked for providing commenting on an earlier version 304 which significantly improved the manuscript. The Fukai site was named in reference to a 305 poisonous jungle of the same name in the film "Nausicaä of the Valley of the Wind" (Studio 306 Ghibli, 1984); the director Hayao Miyazaki and Studio Ghibli are gratefully acknowledged for 307 being a great source of inspiration. 


\section{References}

309

310

311

312

313

314

315

316

317

318

319

320

321

322

323

324

325

326

327

328

329

330

331

332

333

334

335

336

337

338

339

340

341

Chen C, Watanabe HK, Ohara Y. 2016. A very deep Provanna (Gastropoda: Abyssochrysoidea) discovered from the Shinkai Seep Field, Southern Mariana Forearc. Journal of the Marine Biological Association of the United Kingdom. DOI: 10.1017/S0025315416001648.

Egorov R. 1993. Trophoninae (Muricidae) of Russian and adjacent seas. Ruthenica Supplement 1: 1-48.

Folmer O, Black M, Hoeh W, Lutz R, Vrijenhoek R. 1994. DNA primers for amplification of mitochondrial cytochrome c oxidase subunit I from diverse metazoan invertebrates. Molecular Marine Biology and Biotechnology 3: 294-299.

Grassle JF. 1987. The ecology of deep-sea hydrothermal vent communities. In: Blaxter JHS and Southward AJ, eds. Advances in Marine Biology: Academic Press. 301-362.

Hasegawa K. 2009. Upper bathyal gastropods of the Pacific coast of northern Honshu, Japan, chiefly collected by R/V Wakataka-maru. In: Fujita T, ed. Deep-sea fauna and pollutants off Pacific Coast of northern Japan. Tokyo: National Museum of Nature and Science Monographs 39. 225383.

Hasegawa K, Saito H. 1995. Illustrations and annotated checklist of the molluscan type specimens contained in the Sakurai collection in the National Science Museum, Tokyo. National Science Museum, Tokyo: Tokyo.

Hashimoto J, Ohta S, Fujikura K, Miura T. 1995. Microdistribution pattern and biogeography of the hydrothermal vent communities of the Minami-Ensei Knoll in the mid-Okinawa trough, Western Pacific. Deep Sea Research Part I: Oceanographic Research Papers 42: 577-598.

Higo S, Callomon P, Goto Y. 1999. Catalogue and bibliography of the marine shell-bearing Mollusca of Japan. Elle Scientific Publications: Osaka.

Higo S, Callomon P, Goto Y. 2001. Catalogue and bibliography of the marine shell-bearing mollusca of Japan: Type figures. Elle Scientific Publications: Osaka.

Houart R, Sellanes J. 2006. New data on recently described Chilean trophonines (Gastropoda: Muricidae), with the description of a new species and notes of their occurrence at a cold-seep site. Zootaxa 1222: 53-68.

Ise Y. 2012. Chapter 5: Porifera. In: Fujikura K, Okutani $\mathrm{T}$ and Maruyama $\mathrm{T}$, eds. Deep-sea life Biological observations using research submersibles (2nd Edition). Tokyo: Tokai University Press.

Kawagucci S, Kumagai H, Nakamura K, Miyazaki J, Kitada K, Torimoto J, Makabe A, Chen C, Kitahashi T, Fujiwara T, Tsu Tsumi S, Iwamoto H. 2015. KR15-16 cruise report. ROV survey of new hydrothermal vent(s) at mid- and southern-Okinawa Trough, as a part of SIP. In: JAMSTEC, ed. R/V Kairei Cruise Report. Yokosuka: Japan Agency for Marine-Earth Science and 
http://www.godac.jamstec.go.jp/catalog/data/doc_catalog/media/KR15-16_all.pdf.

Layton KKS, Martel AL, Hebert PDN. 2014. Patterns of DNA barcode variation in Canadian marine molluscs. PLOS ONE 9: e95003.

\section{Levin LA, Baco AR, Bowden DA, Colaco A, Cordes EE, Cunha MR, Demopoulos AWJ, Gobin J,} Grupe BM, Le J, Metaxas A, Netburn AN, Rouse GW, Thurber AR, Tunnicliffe V, Van Dover CL, Vanreusel A, and Watling L. 2016. Hydrothermal vents and methane seeps: Rethinking the sphere of influence. Frontiers in Marine Science 3: 72.

Levin LA, Orphan VJ, Rouse GW, Rathburn AE, Ussler W, Cook GS, Goffredi SK, Perez EM, Waren A, Grupe BM, Chadwick G, Strickrott B. 2012. A hydrothermal seep on the Costa Rica margin: middle ground in a continuum of reducing ecosystems. Proceedings of the Royal Society B: Biological Sciences 279: 2580-2588.

Lutz RA, Kennish MJ. 1993. Ecology of deep-sea hydrothermal vent communities: A review. Reviews of Geophysics 31: 211-242.

Makabe A, Tasumi E, Matsui Y, Horai S, Sato S, Chen C, Shibuya T, Kitada K, Takahashi A, Miyazaki J, Nakamura K, Kawagucci S, Kumagai H. 2017. Geochemical and biological features of hydrothermal vent fields newly discovered in the Okinawa Trough. Goldschmidt Conference Abstracts 2017: Poster 2331, available from: https://goldschmidt.info/2017/abstracts/abstractView?id=2017005519.

Makabe A, Tsutsumi S, Chen C, Torimoto J, Matsui Y, Shibuya T, Miyazaki J, Kitada K, Kawagucci S. 2016. Discovery of new hydrothermal vent fields in the mid- and southern-Okinawa Trough. Goldschmidt Conference Abstracts 2016: 1945, available from: https://goldschmidt.info/2016/uploads/abstracts/finalPDFs/1945.pdf.

Marshall BA. 1995. A revision of the recent Calliostomatidae of New Zealand (Mollusca: Gastropoda: Trochoidea). The Nautilus 108: 83-126.

Marshall BA. 2016. New species of Venustatrochus Powell, 1951 from New Zealand, and new species of Falsimargarita Powell, 1951 and a new genus of the Calliostomatidae from the southwest Pacific, with comments on some other calliostomatid genera (Mollusca: Gastropoda). Molluscan Research 36: $119-141$.

Merle D, Garrigues B, Pointier J-P. 2011. Fossil and recent Muricidae of the world: Part Muricinae. ConchBooks: Hackenheim.

Meyer CP, Paulay G. 2005. DNA barcoding: Error rates based on comprehensive sampling. PLOS Biology 3: e422.

Miyazaki J, Makabe A, Nakamura K, Chen C, Tasumi E, Fujiwara T, Horai S, Sato S, Inoue S, Hashimoto Y. 2016. KR16-16 cruise report. Cross-ministerial Strategic Innovation Promotion Program (SIP) Next-Generation Technology for Ocean Resources Exploration: Seeking and 
Hunting the Hydrothermal Activities in Southern Okinawa Trough In: JAMSTEC, ed. $R / V$ Kairei Cruise Report. Yokosuka: Japan Agency for Marine-Earth Science and Technology (JAMSTEC), available from: http://www.godac.jamstec.go.jp/catalog/data/doc_catalog/media/KR16-16_all.pdf.

Nakamura K, Kawagucci S, Kitada K, Kumagai H, Takai K, Okino K. 2015. Water column imaging with multibeam echo-sounding in the mid-Okinawa Trough: Implications for distribution of deepsea hydrothermal vent sites and the cause of acoustic water column anomaly. Geochemical Journal 49: 579-596.

Okutani T. 1959. A new muricid gastropod, Trophonopsis soyoae, sp. nov. from a deep water in KumanoNada, Japan. Venus 20: 350-352.

Okutani T, Iwahori A. 1992. Noteworthy gastropods collected from bathyal zone in Tosa Bay by the R/V Kotaka-Maru in 1987 and 1988. Venus 51: 235-268.

Petersen JM, Zielinski FU, Pape T, Seifert R, Moraru C, Amann R, Hourdez S, Girguis PR, Wankel SD, Barbe V, Pelletier E, Fink D, Borowski C, Bach W, Dubilier N. 2011. Hydrogen is an energy source for hydrothermal vent symbioses. Nature 476: 176-180.

Sakurai K. 1996. Eight new species of trochid genera, Tristichotrochus, Kombologion and Otukaia (Calliostomatinae) from Japan and adjacent waters. Venus 53: 287-296.

Sarrazin J, Robigou V, Juniper SK, and Delaney JR. 1997. Biological and geological dynamics over four years on a high-temperature sulfide structure at the Juan de Fuca Ridge hydrothermal observatory. Marine Ecology Progress Series 153:5-24. 10.3354/meps153005

Sasaki T, Warén A, Kano Y, Okutani T, Fujikura K, Kiel S. 2010. Gastropods from recent hot vents and cold seeps: systematics, diversity and life strategies. In: Kiel S, ed. The vent and seep biota. Netherlands: Springer 169-254.

Sellanes J, Quiroga E, Neira C. 2008. Megafauna community structure and trophic relationships at the recently discovered Concepción Methane Seep Area, Chile, $\sim 36^{\circ}$ S. ICES Journal of Marine Science 65: 1102-1111.

Tsuchiya K. 2017. Muricidae. In: Okutani T, ed. Marine mollusks in Japan (2nd Editon). Tokyo: Tokai University Press. 282-310.

Tunnicliffe V, and Fontaine AR. 1987. Faunal composition and organic surface encrustations at hydrothermal vents on the southern Juan De Fuca Ridge. Journal of Geophysical Research: Solid Earth 92:11303-11314.

Van Dover CL. 2000. The ecology of deep-sea hydrothermal vents. Princeton University Press: Princeton.

Van Dover CL, and Trask JL. 2000. Diversity at deep-sea hydrothermal vent and intertidal mussel beds. Marine Ecology Progress Series 195:169-178.

Vilvens C. 2014. New species and new records of Calliostomatidae (Gastropoda: Trochoidea) from eastern and central Indo-Pacific. Novapex 15: 37-48. 
413 Warén A, Bouchet P. 2001. Gastropoda and Monoplacophora from hydrothermal vents and seeps new 414 taxa and records. The Veliger 44: 116-231.

415 Watanabe H, Kojima S. 2015. Vent fauna in the Okinawa Trough. In: Ishibashi J-i, Okino K and 416 Sunamura M, eds. Subseafloor Biosphere Linked to Hydrothermal Systems: TAIGA Concept. 417 Tokyo: Springer Japan. 449-459.

418 Williams ST, Donald KM, Spencer HG, Nakano T. 2010. Molecular systematics of the marine 419 gastropod families Trochidae and Calliostomatidae (Mollusca: Superfamily Trochoidea). $420 \quad$ Molecular Phylogenetics and Evolution 54: 783-809. 
422 Figure 1. Map of the Okinawa Trough and surrounding areas showing locations of the two 423 relevant hydrothermally influenced sites. The blue star indicates Fukai site, Higashi-Ensei and the 424 red dot indicates Crane site, Tarama Hill. Black dots indicate known vent sites in the Okinawa 425 Trough (following Watanabe \& Kojima, 2015). Site name abbreviations are as follows: $\mathrm{Cr}=$ 426 Crane Site, Ht = Hatoma Knoll, Ih = Iheya Ridge, Ik = Iheya North Knoll, Ir = Irabu Knoll, Iz = 427 Izena Hole, $\mathrm{Me}=$ Minami-Ensei Knoll, $\mathrm{Yg}=$ Daiyon-Yonaguni Knoll, $\mathrm{Yr}=$ Yoron Hole. Original $428500 \mathrm{~m}$ mesh data originally obtained by Japan Coast Guard and publicly available from Japan 429 Oceanographic Data Center (http://jdoss1.jodc.go.jp/vpage/depth500 file j.html).

430 Figure 2. In situ photographs of the two hydrothermally influenced sites. A-B: Fukai site, 431 Higashi-Ensei; A: Overview, B: Close-up; the black arrowhead indicates Otukaia ikukoae and the 432 white arrowhead indicates Abyssotrophon cf. soyoae. C-D: Crane site, Tarama Hill; C: Overview, 433 D: Close-up; the white arrowhead indicates Abyssotrophon soyoae. The cut-out photographs are 434 magnified images of gastropods seen at each site.

435 Figure 3. Specimens of the two gastropods collected from hydrothermally influenced areas. A436 D: Otukaia ikukoae from Fukai site, Higashi-Ensei. E-J: Abyssotrophon soyoae from Crane site, 437 Tarama Hill; $\mathbf{E}-\mathbf{H}=$ Specimen \#1, $\mathbf{I}, \mathbf{J}=$ Specimen \#2. Scale bars: $\mathbf{A}-\mathbf{D}=1 \mathrm{~cm}, \mathbf{E}-\mathbf{J}=0.5 \mathrm{~cm}$.

438 Figure 4. Scanning electron micrographs of radulae. A: Otukaia ikukoae from Fukai site, 439 Higashi-Ensei. B: Abyssotrophon soyoae from Crane site, Tarama Hill. Scale bars: A $=500 \mu \mathrm{m}$, $440 \quad \mathbf{B}=50 \mu \mathrm{m}$. 


\section{Figure 1}

Map of the Okinawa Trough and surrounding areas showing locations of the two relevant hydrothermally influenced site.

The blue star indicates Fukai site, Higashi-Ensei and the red dot indicates Crane site, Tarama Hill. Black dots indicate known vent sites in the Okinawa Trough (following Watanabe \& Kojima, 2015). Site name abbreviations are as follows: $\mathrm{Cr}=$ Crane Site, $\mathrm{Ht}=$ Hatoma Knoll, Ih $=$ Iheya Ridge, I $\mathrm{k}=$ Iheya North Knoll, Ir = Irabu Knoll, Iz = Izena Hole, Me = Minami-Ensei Knoll, $\mathrm{Yg}=$ Daiyon-Yonaguni Knoll, $\mathrm{Yr}=$ Yoron Hole. Original $500 \mathrm{~m}$ mesh data originally obtained by Japan Coast Guard and publicly available from Japan Oceanographic Data Center (http://jdoss1.jodc.go.jp/vpage/depth500_file_j.html). 


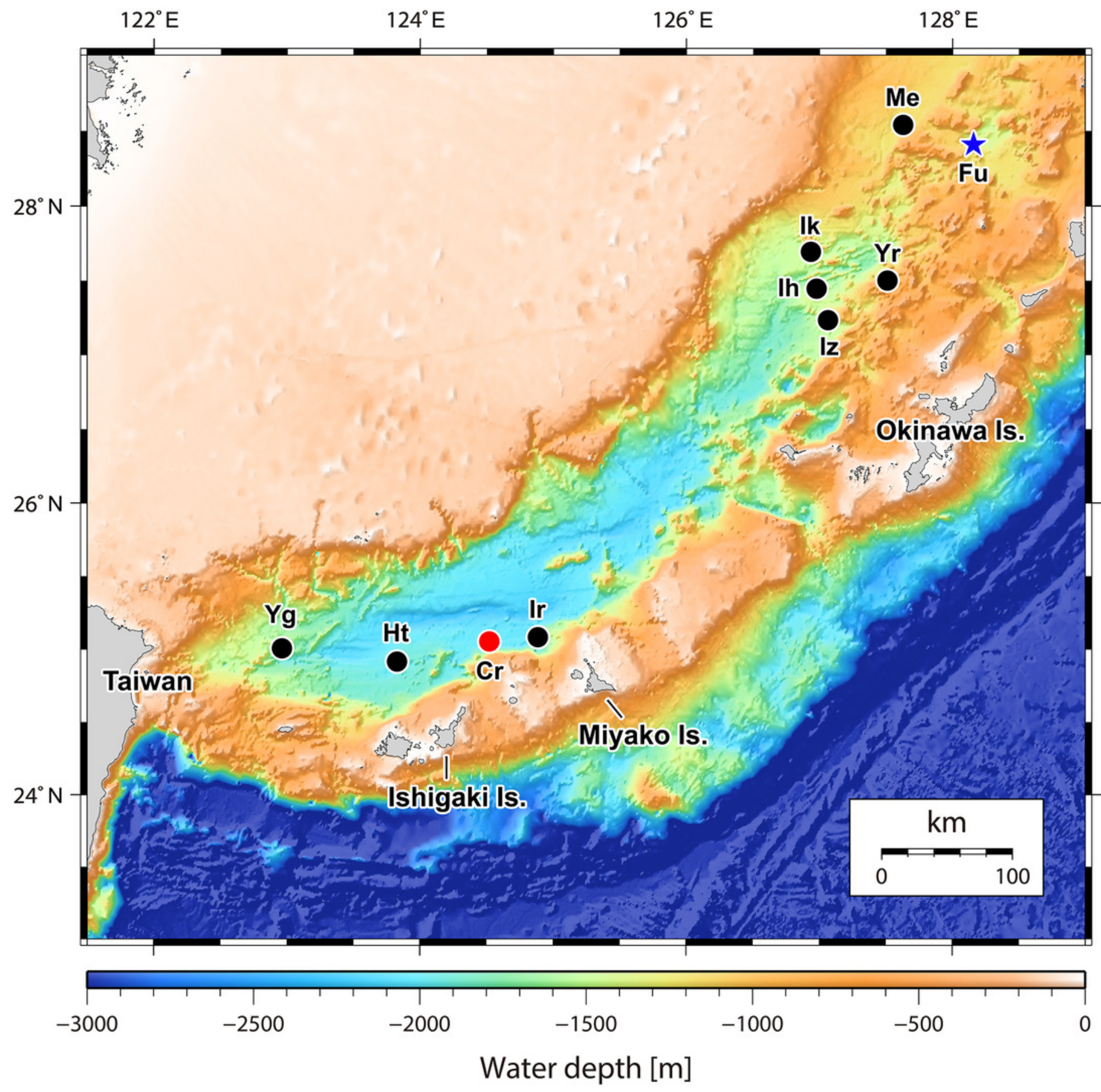




\section{Figure 2}

In situ photographs of the two hydrothermally influenced sites.

A-B: Fukai site, Higashi-Ensei; A: Overview, B: Close-up; the black arrowhead indicates

Tristichotrochus ikukoae and the white arrowhead indicates Abyssotrophon cf. soyoae. C-D:

Crane site, Tarama Hill; C: Overview, D: Close-up; the white arrowhead indicates

Abyssotrophon soyoae. The cut-out photographs are magnified images of gastropods seen at each site.
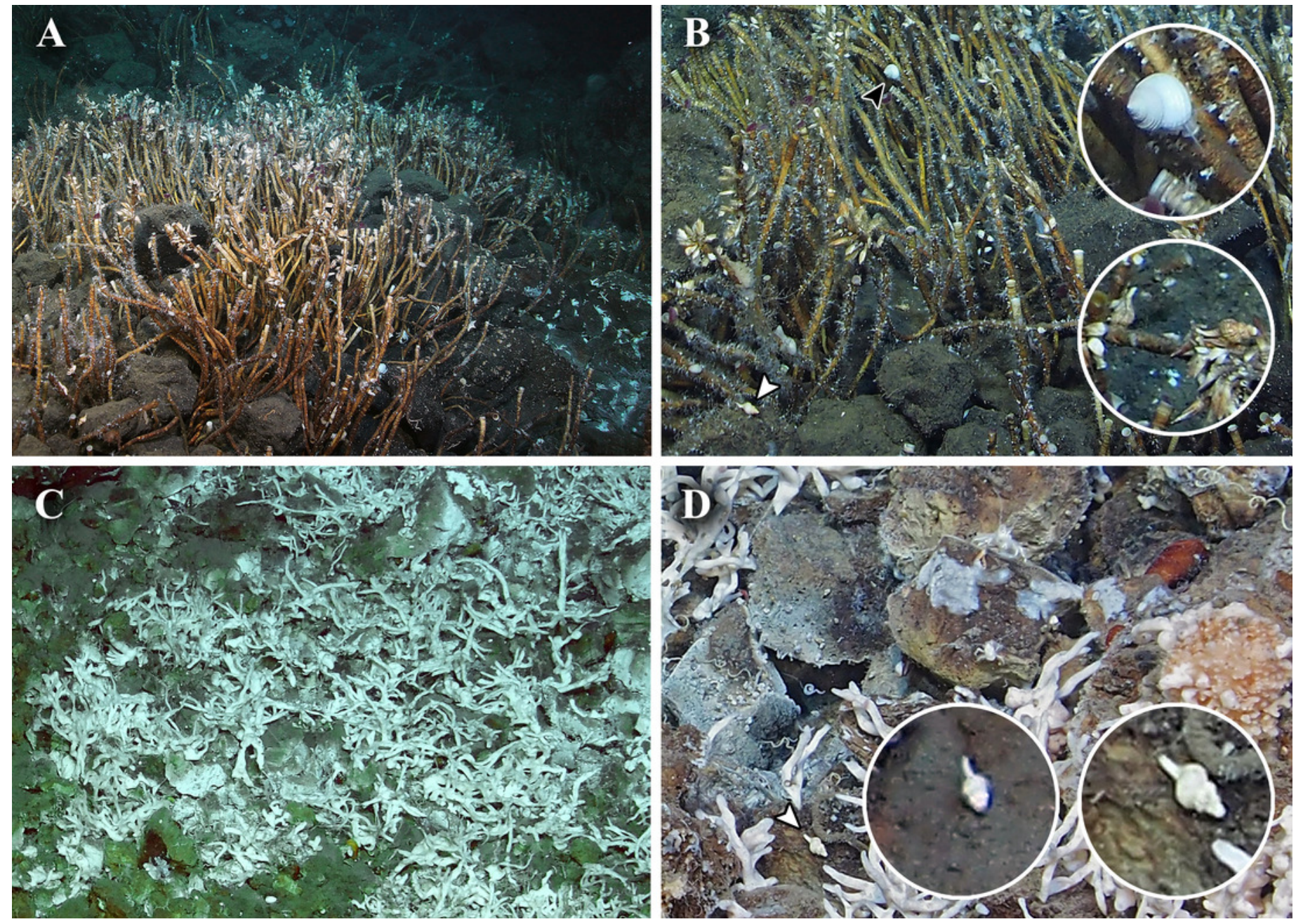


\section{Figure 3}

Specimens of the two gastropods collected from hydrothermally influenced areas.

A-D: Tristichotrochus ikukoae from Fukai site, Higashi-Ensei. E-J: Abyssotrophon soyoae from Crane site, Tarama Hill; E-H = Specimen \#1, I, J = Specimen \#2. Scale bars: A-D = $1 \mathrm{~cm}, \mathbf{E}-\mathbf{J}$ $=0.5 \mathrm{~cm}$.

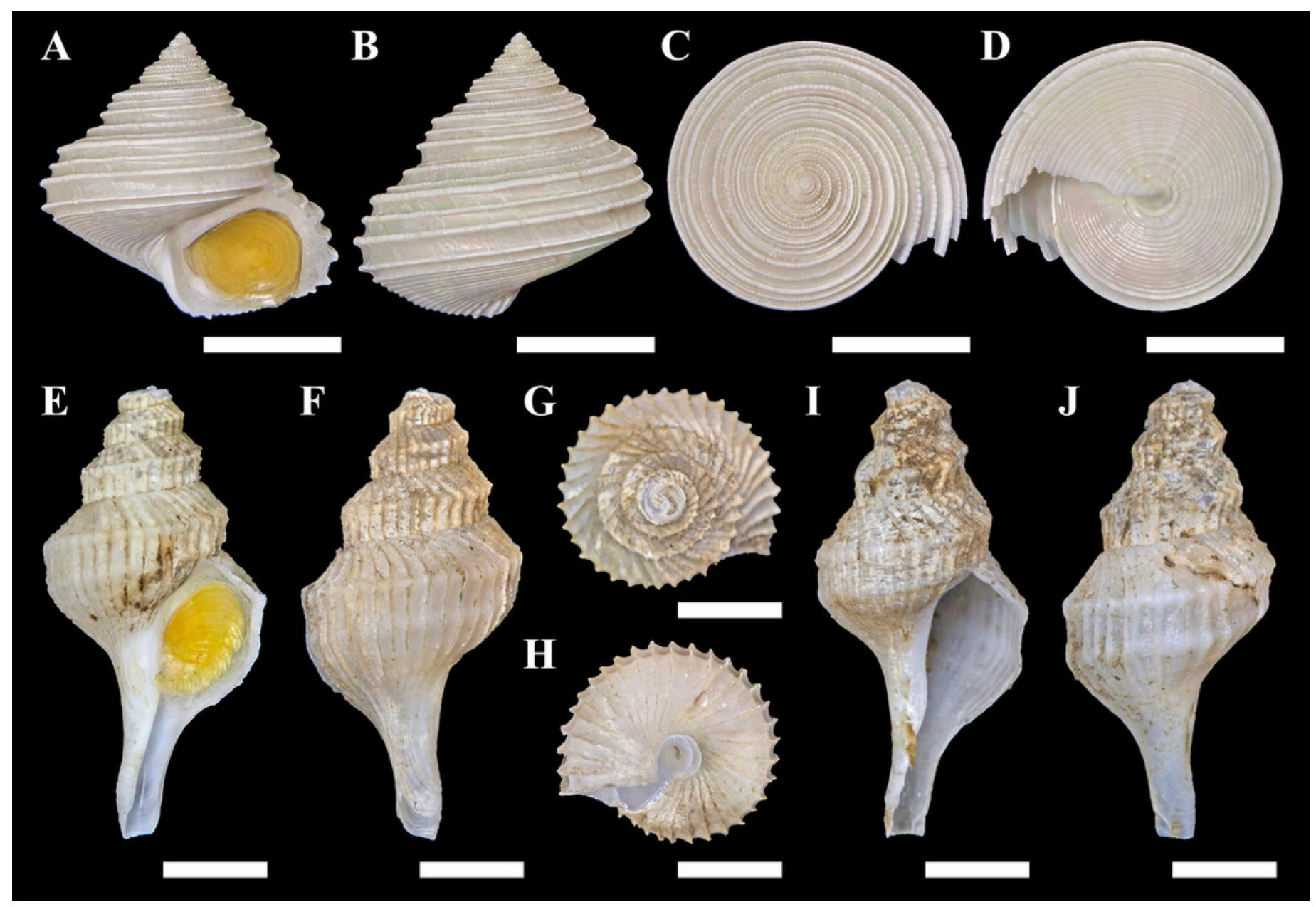




\section{Figure 4}

Scanning electron micrographs of radulae.

A: Tristichotrochus ikukoae from Fukai site, Higashi-Ensei. B: Abyssotrophon soyoae from Crane site, Tarama Hill. Scale bars: $\mathbf{A}=500 \mu \mathrm{m}, \mathbf{B}=50 \mu \mathrm{m}$.

*Note: Auto Gamma Correction was used for the image. This only affects the reviewing manuscript. See original source image if needed for review. 

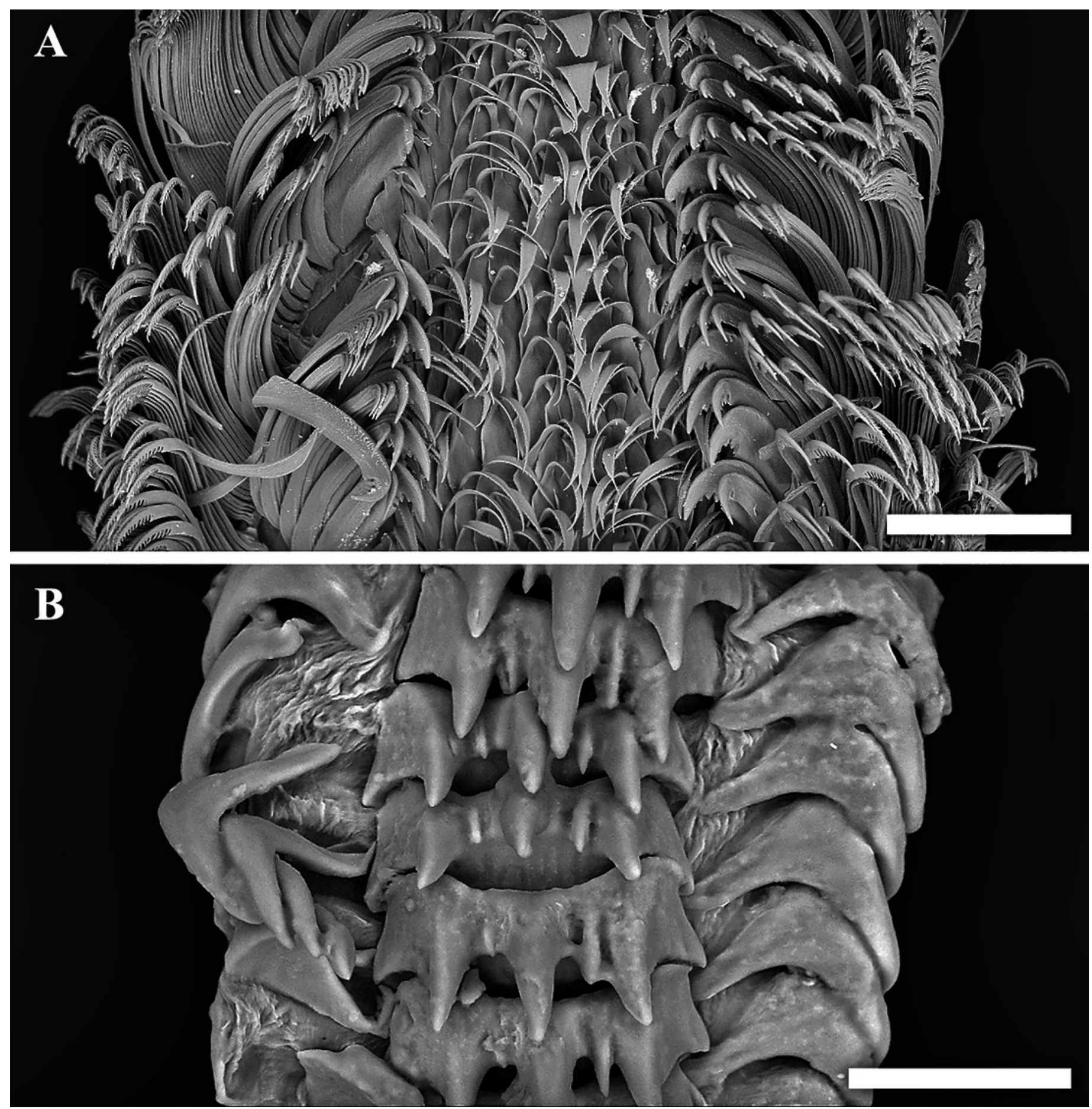